\title{
Doing facial difference
}

Citation for published version (APA):

Yaron, G. (2018). Doing facial difference: The lived experiences of individuals with facial limb absence. [Doctoral Thesis, Maastricht University]. Datawyse / Universitaire Pers Maastricht.

https://doi.org/10.26481/dis.20180608yg

Document status and date:

Published: 01/01/2018

DOI:

10.26481/dis.20180608yg

Document Version:

Publisher's PDF, also known as Version of record

\section{Please check the document version of this publication:}

- A submitted manuscript is the version of the article upon submission and before peer-review. There can be important differences between the submitted version and the official published version of record.

People interested in the research are advised to contact the author for the final version of the publication, or visit the DOI to the publisher's website.

- The final author version and the galley proof are versions of the publication after peer review.

- The final published version features the final layout of the paper including the volume, issue and page numbers.

Link to publication

\footnotetext{
General rights rights.

- You may freely distribute the URL identifying the publication in the public portal. please follow below link for the End User Agreement:

www.umlib.nl/taverne-license

Take down policy

If you believe that this document breaches copyright please contact us at:

repository@maastrichtuniversity.nl

providing details and we will investigate your claim.
}

Copyright and moral rights for the publications made accessible in the public portal are retained by the authors and/or other copyright owners and it is a condition of accessing publications that users recognise and abide by the legal requirements associated with these

- Users may download and print one copy of any publication from the public portal for the purpose of private study or research.

- You may not further distribute the material or use it for any profit-making activity or commercial gain

If the publication is distributed under the terms of Article $25 \mathrm{fa}$ of the Dutch Copyright Act, indicated by the "Taverne" license above, 


\section{Samenvatting}

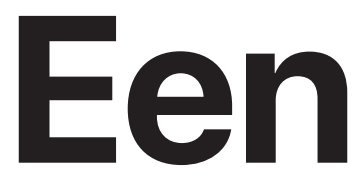

veranderd

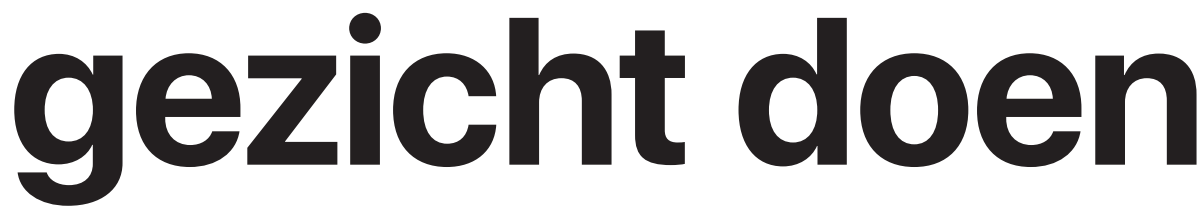

De geleefde ervaringen van individuen met een gedeeltelijke aangezichtsamputatie 
Wat betekent het om een ander gezicht te hebben-een gezicht dat is getekend door een afwijking? In dit proefschrift onderzoek ik deze vraag door middel van een empirisch-filosofische studie naar de geleefde ervaringen van mensen met een deels geamputeerd gezicht. Deze studie is empirisch in de zin dat ze uitgaat van interviews met twintig individuen die een of meerdere delen van het gezicht missen. De studie is filosofisch omdat haar ontwerp en de erin uitgevoerde analyses vertrekken vanuit een reeks geesteswetenschappelijke en sociaalwetenschappelijke theorieën over het lichaam, technologische hulpmiddelen en de sociaal-culturele betekenis van beperking. In de voorgaande hoofdstukken heb ik de studie en mijn bevindingen gepresenteerd. De komende pagina's geven een korte samenvatting van mijn onderzoek.

Hoofdstuk een introduceert het onderwerp van de studie, positioneert haar ten opzichte van bestaand onderzoek naar gelaatsafwijkingen, bespreekt het gebruikte theoretische kader en gaat in op de toegepaste methode. Zoals ik in dit hoofdstuk laat zien, is er vooralsnog weinig onderzoek gedaan naar de ervaringen van mensen met een deels geamputeerd gezicht. Er bestaan wel studies naar de bredere categorie 'gelaatsafwijkingen', maar deze hebben over het algemeen een medische of psychosociale insteek. Medisch onderzoek belicht doorgaans de onderliggende oorzaken, diagnose, typische ontwikkeling, behandeling en verwachte uitkomsten bij aandoeningen die het gelaat aantasten. Daarnaast geven zulke studies meestal ook schattingen van het aantal nieuwe gevallen in een bepaalde periode (incidentie) en het totale aantal bestaande gevallen (prevalentie). Om de impact van dergelijke aandoeningen te bepalen, meten medische studies de kwaliteit van leven van aangedane individuen door parameters als pijn, functiestoornissen, ervaren ziektelast en geestelijke gezondheid in kaart te brengen. De psychosociale benadering van gelaatsafwijkingen zoomt verder in op de geestelijke gezondheid en sociale positie van mensen met een zichtbaar andere uiterlijk. Met name de psychologie van het uiterlijk heeft zich in de afgelopen twintig jaar ontwikkeld als een sociaalwetenschappelijke discipline die de psychische gevolgen (zoals sociale angst, psychosociale coping mechanismen en depressie) van een zichtbare afwijking onderzoekt.

Medische en psychosociale studies naar aandoeningen die het gezicht aantasten geven inzicht in een aantal zaken die samenhangen met gelaatsafwijking. Maar leven met een ongewoon gezicht behelst meer dan: mensen met een ander gezicht hebben namelijk te maken met uitdagingen die vooral tot uiting komen in hun dagelijkse leven. Zo kampen ze met de gevolgen van allerlei functiestoornissen en hun soms radicaal veranderd uiterlijk. Om te achterhalen wat het betekent om te leven met een ander gezicht is het dus noodzakelijk om te onderzoeken welke rol deze uitdagingen spelen in het dagelijkse leven van aangedane individuen. Het gaat dan om hoe mensen met ander gezicht hun eigen lichaam en de wereld ervaren. Vooralsnog zijn de alledaagse, geleefde ervaringen van mensen met een afwijking in het gezicht amper in de wetenschappelijke literatuur verkend. In dit proefschrift vul ik deze leemte. 
Om dit te doen, heb ik semigestructureerde diepte-interviews gehouden met twintig individuen (acht vrouwen en twaalf mannen tussen de 42 en 84 jaar oud) die een gedeeltelijke aangezichtsamputatie hebben ondergaan en een gelaatsprothese dragen. De respondenten zijn geworven via de prothetiekafdeling van een ziekenhuis in een grote Nederlandse stad. De interviews werden uitgevoerd in hun eigen huis of op een andere vertrouwde locatie. Vaak nam ook de partner deel aan het vraaggesprek. Gedurende de interviews maakte ik gebruik van een topiclijst om deelnemers aan het onderzoek te laten vertellen over de rol van hun veranderde gezicht in hun dagelijks leven. Naast de interviews bezocht ik herhaaldelijk het ziekenhuis zelf, evenals drie verschillende prothetiekateliers in Nederland en België. Via de observaties die ik in deze locaties uitvoerde kreeg ik om een indruk van het klinische traject dat wordt doorlopen door de participanten.

Bij het analyseren van de interviews paste ik een zogeheten 'thematische analyse' (TA) toe. Daarnaast liet ik me leiden door de benadering die centraal staat in 'interpretatieve fenomenologische analyse' (IPA), een methode voor de narratieve analyse van interviews die voortkomt uit de fenomenologische traditie. IPA legt bijzondere nadruk op de subjectieve manier waarop mensen betekenis geven aan hun ervaringen, vooral met betrekking tot een ingrijpende, levens-veranderende gebeurtenis. Mijn analyses richtten zich dan ook op de manier waarop respondenten hun soms radicaal veranderde lichaam en wereld beleven, en hoe zij zich tot deze veranderingen verhouden. Bij het duiden van interviewdata gebruikte ik specifieke inzichten vanuit drie geesteswetenschappelijke en sociaalwetenschappelijke theorieën, te weten fenomenologie, postfenomenologie en disability studies. Elk van deze kaders kan namelijk worden ingezet om kenmerkende aspecten van de ervaringen van respondenten te belichten. De fenomenologie, en dan vooral de fenomenologie van ziekte en beperking, verleent inzicht in de manier waarop het belichaamd-zijn-in-de-wereld van mensen verandert door een medische aandoening. De postfenomenologie wijst op de rol van technologische hulpmiddelen hierin. Disability studies onthult hoe allerlei discriminatoire sociale normen en aannames rondom lichamelijke beperking tot uiting komen in het dagelijkse leven. In de drie empirische hoofdstukken van dit proefschrift gebruik ik deze theoretische kaders om de ervaringen van de participanten te verkennen.

In hoofdstuk twee zoom ik in op de manier waarop gelaatsafwijking belichaamd is. Het aanpassen aan een veranderd gezicht is immers niet alleen een psychosociale aangelegenheid, maar omvat ook een lichamelijke dimensie. Ik begin door te vragen hoe de fenomenologie van het lichaam kan worden toegepast op de casus van mensen met een gedeeltelijk geamputeerd gezicht. De fenomenologie van het lichaam neemt als uitgangspunt de betrekkelijke afwezigheid van het gezonde lichaam. Fenomenologen Maurice Merleau-Ponty en Drew Leder laten zien dat mensen in het dagelijkse leven normaal gesproken niet hun eigen lichaam, maar veeleer de wereld ervaren-een ervaring die echter wel mogelijk wordt gemaakt door de zintuigelijke capaciteiten en het bewegingsapparaat van dat lichaam. Deze uitwendige oriëntatie wordt gekarakteriseerd door een impliciet vertrouwen in het eigen vermogen om allerlei taken en activiteiten aan te pak- 
ken. Fenomenologen noemen deze houding van lichamelijke competentie ook wel het 'ik kan'. Maar als het lichaam ziek of beperkt is komt de afwezigheid ervan in het gedrang. Pijn, zwakte of andere klachten vragen dan om aandacht, waardoor het lichaam in het bewustzijn verschijnt. Een dergelijke zelf-georiënteerde focus kan ook optreden wanneer het lichaam wordt bekeken door een ander. De zichtbaarheid van het lichaam leidt dan soms tot een ongemakkelijk zelfbewustzijn.

Door deze inzichten toe te passen op de interviews laat ik zien dat het ongewone gezicht van de deelnemers in mijn studie regelmatig verschijnt in hun bewustzijn wanneer het aanleiding geeft tot verstorende percepties, sensaties of observaties van anderen. Dit gaat ten koste van hun vermogen om zich volle wikkelen. Zo leren zij op een nieuwe manier te bewegen en handelen om ongelukjes te voorkomen, leren zij om onprettige sensaties zoals (fantoom)pijn of jeuk te managen en vinden ze manieren om zich te verhouden tot de aandacht van anderen. Deze lichamelijke gewoontes hebben als doel om de afwezigheid van het lichaam te herwinnen of vormen een manier om met de verstorende aanwezigheid ervan om te gaan. Via deze gewoontes 'belichamen' de deelnemers aan mijn studie als het ware hun ongewone gezicht. Door de lichamelijke dimensies van een gedeeltelijke aangezichtsamputatie te belichten, vult dit hoofdstuk de gangbare medische en psychosociale benaderingen van gelaatsafwijkingen aan. Bovendien laat dit hoofdstuk zien dat er geen strikte grens te trekken is tussen functionele aanpassingen en aanpassingen gericht op het uiterlijk, omdat beide vorm krijgen via lichamelijke gewoontes. Het hoofdstuk demonstreert ten slotte ook hoe de fenomenologie van het lichaam niet alleen fysieke beperkingen kan adresseren, maar ook kwesties die samengaan met de afwijkende aanblik van zieke en beperkte lichamen.

Maar omgaan met een veranderd uiterlijk naar aanleiding van een gedeeltelijke aangezichtsamputatie behelst meer dan de ontwikkeling van nieuwe lichamelijke gewoontes. Om de invloed van het veranderde uiterlijk op het dagelijkse leven van respondenten verder te verkennen, onderzoek ik in hoofdstuk drie wat gelaatsprotheses voor hun gebruikers betekenen. Dergelijke ‘cosmetische' protheses stellen geamputeerde mensen in staat om voor 'normaal' te kunnen doorgaan. Maar hoe gebeurt dit precies en wat hebben gebruikers hiermee te winnen? Om dit beter te begrijpen neem ik de verhalen van de deelnemers aan deze studie onder de loep. Ik maak daarbij gebruik van verschillende techniek-filosofische benaderingen om de ervaringen van respondenten te duiden. Zo laat het onderzoek van Myriam Winance zien hoe er samenhang ontstaat tussen technologische hulpmiddelen en de lichamen van gebruikers met een lichamelijke beperking. En het werk van de postfenomenologen Don Ihde en Peter-Paul Verbeek illustreert hoe technologie de relatie tussen lichaam en wereld bemiddelen, omdat het gebruik van allerlei alledaagse apparaten invloed heeft op de manier waarop mensen waarnemen en handelen.

Om te begrijpen welke rol de gelaatsprothese in het dagelijkse leven van de deelnemers aan deze studie speelt, onderzoek ik eerst hoe dit hulpmiddel het normale uiterlijk herstelt. Een gelaatsprothese bootst de aanblik van de ontbrekende onderdelen van het 
gezicht na, waardoor het weer compleet—en dus normaal-lijkt. Of dit 'lukt' is echter sterk afhankelijk van de mate waarin de prothese en het gezicht van haar drager bij elkaar passen. Uit de interviews blijkt dat een dergelijke samenhang niet zondermeer gegeven is, maar inspanning vergt. Respondenten maken dan ook gebruik van wat ik 'paspraktijken' noem om een goede samenhang te laten ontstaan. Paspraktijken behelzen het monitoren of aanpassen van de prothese (voelen of de kunstmatige neus goed vast zit, gerafelde randen bijvijlen). Ze kunnen ook het gebruik van allerlei hulpmiddelen (een bril, make-up) omvatten, die de randen van de prothese camoufleren. Paspraktijken kunnen ten slotte ook betrekking hebben op de beweeglijkheid en ruimtelijke positionering van het gezicht zelf (de schaduw opzoeken). Een goede samenhang van gezicht en hulpmiddel vraagt dus om aanpassingen aan zowel de gebruiker als de prothese. Sommige paspraktijken worden uiteindelijk ingesleten, automatische gewoontes. Andere blijven om bewuste inspanningen vragen. Participanten geven dan ook aan dat ze deze aanpassingen, en vooral ook het plannen en 'gedoe' dat erbij hoort, soms lastig vinden.

Waarom blijven respondenten dan toch werken aan een goede samenhang? Dit, zo toon ik aan, komt omdat een goed passende prothese 'transparant' wordt; zij trekt zich als het ware terug in het gezicht van de drager. Hierdoor oogt zij als een natuurlijk onderdeel van het gezicht in plaats van een kunstmatige toevoeging. Anderen zijn dan in staat om het gezicht van de gebruiker in zijn geheel te zien. Zij kunnen weer de persoon 'in' of 'achter' het gezicht zien, in plaats van gefixeerd te raken op diens anders-zijn. De prothese herstelt dus het effect van 'facialiteit' bij gezichten die minder goed te herkennen zijn als zodanig. Dit levert twee cruciale voordelen op: (a) respondenten slagen erin andermans starende blikken, vragen en opmerkingen te ontwijken, waarmee hun anonimiteit gewaarborgd blijft. Niet langer belemmerd door ongewenste aandacht, herwinnen ze hun bewegingsvrijheid in openbare ruimtes; (b) directe interacties tussen geïnterviewde deelnemers en anderen verlopen vloeiender. De prothese leidt immers minder af dan de amputatie zelf of een meer zichtbare bedekking. Een normaal uiterlijk, wanneer het wordt hersteld met behulp van cosmetische protheses, stelt geamputeerde mensen dus in staat om zich staande te houden in een precaire sociale omgeving. Door het alledaagse gebruik van kunstmatige gezichtsdelen te verkennen, geeft dit hoofdstuk inzicht in de rol van het uiterlijk in de prothetiek. Daarnaast belicht het hoofdstuk hoe intieme technologieën niet alleen onze waarneming en ons vermogen tot handelen bemiddelen, maar ook onze sociale omgang.

De deelnemers in mijn onderzoek rapporteerden echter ook andere ervaringen rondom hun veranderde uiterlijk-ervaringen die samenhangen met de zichtbaarheid van hun anders-zijn. In hoofdstuk vier onderzoek ik dergelijke 'ervaringen van zichtbaarheid'. Deze ervaringen, zoals ik laat zien, hangen samen met de drie verschillende manieren waarop respondenten hun amputatie tonen in sociale situaties, namelijk verborgen onder een zichtbare bedekking, verhuld door middel van de gelaatsprothese, of open en bloot. Deze verschillende manieren waarop zij hun gezicht tonen leiden tot verschillende types interacties met anderen. In dit hoofdstuk bespreek ik ze alle drie. Om de zichtbaar- 
heidservaringen van participanten te duiden, gebruik ik het werk van socioloog Erving Goffman en van disability studies-onderzoeker Rosemarie Garland Thomson. Dit kader geeft inzicht in het stigma rondom lichamen die afwijken van de norm en de aandacht die deze lichamen ten deel valt in openbare ruimtes.

Alle respondenten dragen regelmatig een verband, ooglapje of pleister. In het openbaar trekken dergelijke hulpmiddelen de aandacht van anderen, die dan gaan staren, vragen stellen of (vervelende) opmerkingen maken. Deelnemers geven aan dat ze zich hierdoor schamen voor hun anders-zijn en zich soms ook minderwaardig voelen. Hun reacties op ongewenste aandacht nemen doorgaans drie vormen aan: (a) negeren, (b) een grens aangeven; of (c) een open gesprek aangaan. Zoals boven al duidelijk werd kunnen respondenten ongewenste aandacht vermijden door een goed passende prothese te dragen die hun gezicht herstelt. Hierdoor herwinnen ze hun bewegingsvrijheid. Daarnaast laat een prothetisch hersteld gezicht directe sociale interacties vloeiender verlopen. Maar een hersteld gezicht brengt een derde voordeel met zich mee. Het stelt anderen in staat om participanten te zien als veelzijdige individuen in plaats van gefixeerd te raken op hun zichtbare verschil. Wanneer zij niet langer automatisch worden weggezet als 'tragische gehandicapte', wordt het weer mogelijk om uiteenlopende sociale rollen te vervullen (bijvoorbeeld behulpzame buur of omroeper in sportwedstrijden). Prothetisch herstel is echter allerminst gegeven. Wanneer de prothese en haar drager niet goed op elkaar aansluiten, kan de kunstmatigheid van dit hulpmiddel door anderen worden ontdekt. Dit leidt weer tot ongewenste aandacht. Als zij verwachten dat hun prothese zal worden ontdekt, kiezen sommige participanten ervoor om anderen er alvast over in te lichten. Hiermee houden ze controle en wordt sociaal ongemak voorkomen. Ten slotte kunnen respondenten er ook voor kiezen om hun amputatie te ontbloten. Sommigen doen dit ook regelmatig, maar dan alleen thuis, in aanwezigheid van partners, kinderen en andere naasten. De mogelijkheid om hun gezicht te tonen zoals het is geeft hun het gevoel dat ze geaccepteerd worden ondanks hun anders-zijn. De amputatie doet er dan simpelweg weg niet meer toe.

Uiteindelijk draaien de zichtbaarheidservaringen van de deelnemers aan deze studie om de betekenis die hun ongewone uiterlijk krijgt in interacties met anderen. Via de positie die ze hierbij aannemen, onderhandelen ze in feite over deze betekenis. De inzet van deze onderhandelingen is niets minder dan de mogelijkheid van sociale erkenning. Participanten verzetten zich immers op verschillende manieren tegen andermans pogingen om hen te reduceren tot hun zichtbare verschil. Daarnaast moedigen zij deze anderen aan om hen als 'gewone' mensen te benaderen-veelzijdige actoren die recht hebben op respect en een gelijke behandeling. Dit betekent dat de strijd voor de sociale erkenning van mensen met een beperking zich niet alleen voltrekt op het macroniveau van politieke en maatschappelijke actievoering, maar ook op het microniveau van alledaagse sociale interacties.

In hoofdstuk vijf breng ik de verschillende strengen die door de drie empirische hoofdstukken lopen bij elkaar. Ik stel vast dat leren omgaan met een ongewoon gelaat om een actieve benadering vraagt. Dit noem ik ook wel het 'doen' van verschil. Om te begrijpen wat 
dit doen behelst, neem ik in dit hoofdstuk een aantal gerelateerde concepten in ogenschouw. Zo laat het werk van de sociologen Candice West, Don Zimmerman en Sarah Fenstermaker zien dat mensen hun sociale identiteiten tot stand brengen in interacties met anderen. Taalfilosoof Judith Butler toont aan dat dit veelal gebeurt via performatieve taaluitingen-taaluitingen die de sociale realiteit produceren. Fenomenoloog Iris Marion Young wijst op het feit dat de manier waarop mensen hun lichaam ervaren, bewonen en gebruiken wordt bepaald door sociale normen, maar ook door de fysieke (on)mogelijkheden van het lichaam zelf. Wetenschapsfilosoof Annemarie Mol, ten slotte, belicht de rol van materiële artefacten en de omgeving in de manier waarop (zieke) lichamen vormkrijgen. Door deze inzichten toe te passen op mijn bevindingen wordt het mogelijk om recht te doen aan de sociale, belichaamde en materiële dimensies die samenkomen in het dagelijkse doen van het veranderde gezicht.

Een veranderd gezicht 'doen' is dus: allerlei manieren ontwikkelen om de uitdagingen die samengaan met het hebben van een gelaatsafwijking aan te gaan. Op deze wijze verhouden mensen met een ongewoon gezicht zich actief tot hun radicaal en onomkeerbaar veranderde lichaam en wereld. Dit betekent dat leven met een gedeeltelijk geamputeerd gezicht veel dagelijks werk vergt—werk dat herhaaldelijk uitgevoerd moet worden en bovendien nooit af is. Dit inzicht, concludeer ik, is van onschatbare waarde voor zowel patiënten als professionals in de gezondheidszorg. Nieuwe en bestaande patiënten kunnen baat hebben bij toegang tot de geleefde ervaringen van lotgenoten. Ze kunnen zich dan in anderen herkennen, erkenning krijgen voor wat ze zelf hebben meegemaakt en leren van de manier waarop anderen omgaan met uitdagingen. Zorgprofessionals, van hun kant, kunnen deze geleefde ervaringen gebruiken om te begrijpen hoe ziekte en beperking betekenis krijgen in het dagelijks leven van hun patiënten. Dit inzicht kunnen ze inzetten bij het bieden van voorlichting, (na)zorg en begeleiding. Patiënten kunnen zich dan beter voorbereiden op het voortdurende werk dat ze te wachten staat, en meer steun ondervinden bij het omgaan met dit werk. 
